\title{
MicroRNA-454-3p inhibits cell proliferation and invasion in esophageal cancer by targeting insulin-like growth factor 2 mRNA-binding protein 1
}

\author{
AITING YAN ${ }^{1}$, CUIZHU WANG $^{1}$, LIANGFENG ZHENG $^{2}$, JIEBO ZHOU $^{1}$ and YAN ZHANG ${ }^{1}$ \\ ${ }^{1}$ Department of Oncology and ${ }^{2}$ Central Laboratory, \\ Affiliated Haian Hospital of Nantong University, Nantong, Jiangsu 226600, P.R. China
}

Received August 30, 2019; Accepted July 22, 2020

DOI: $10.3892 / \mathrm{ol} .2020 .12223$

\begin{abstract}
Esophageal cancer (ESCA) is the eighth most common cause of cancer-associated mortality in humans. An increasing number of studies have demonstrated that microRNAs (miRs) serve important roles in mediating tumor initiation and progression. miR-454-3p has been found to be involved in the development of various human malignancies; however, little is known about the role of miR-454-3p in esophageal cancer. In the present study, the protein and gene expression levels of miR-454-3p in ESCA tissues and cells were downregulated compared with adjacent normal tissues and normal human esophageal epithelial cells. Additionally, miR-454-3p downregulation resulted in improved survival rates in patients with ESCA, and miR-454-3p overexpression significantly suppressed cell proliferation, migration and invasion and promoted apoptosis in four ESCA cell lines (EC9706, ECA109, TE-1 and TE-8). It was found that miR-454-3p overexpression inhibited the expression of insulin-like growth factor $2 \mathrm{mRNA}$-binding protein 1 (IGF2BP1) at the protein and mRNA expression levels. Furthermore, it was demonstrated that miR-454-3p inhibited ESCA cell proliferation, migration and apoptosis by targeting IGF2BP1 via the ERK and AKT signaling pathways in a subcutaneous xenograft tumor mouse model. These results showed that miR-454-3p functioned as an important tumor suppressor in ESCA by targeting IGFBP1. Therefore, miR-454-3p may be a novel prognostic biomarker and therapeutic target for patients with ESCA.
\end{abstract}

Correspondence to: Dr Yan Zhang, Department of Oncology, Affiliated Haian Hospital of Nantong University, 17 Zhongbazhong Road, Nantong, Jiangsu 226600, P.R. China

E-mail: yanZhangshj@163.com

Abbreviations: ESCA, esophageal cancer; IGF2BP1, insulin-like growth factor 2 mRNA-binding protein 1; miR, microRNA

Key words: miR-454-3p, esophageal cancer, IGF2BP1, AKT and ERK pathway

\section{Introduction}

Esophageal cancer (ESCA) is the eighth leading cause of cancer-associated death worldwide. Approximately 480,000 new cases and $>400,000$ ESCA-associated deaths occur every year, of which $>80 \%$ of ESCA cases occur in developing countries, and the incidence and mortality of ESCA is highest in China $(1,2)$. Traditional treatment of ESCA, such as chemotherapy, radiation therapy and immunotherapy, does not result in an improved prognosis due to drug resistance and recurrence (3). Therefore, it is necessary to investigate the molecular pathogenesis of ESCA and identify effective prognostic biomarkers and molecular targets for the treatment of ESCA.

MicroRNAs (miRNAs/miRs), a type of short non-coding RNA molecule, are 21-25 nucleotides in length (4). Mature miRNAs can function as oncogenes or tumor suppressors and participate in the regulation of the cell proliferation, migration, apoptosis, metabolism and other cellular responses by binding to the 3'-untranslated region (UTR) of target genes via complementary base pair interactions $(5,6)$. Thus, exploring the underlying molecular mechanisms of miRNA functions is a promising strategy to improve our understanding of the pathogenesis of ESCA, and to identify novel biomarkers for ESCA diagnosis and treatment.

miR-454-3p is a subunit of miR-454 family that functions in tumor initiation, invasion and metastasis. miR-454-3p has been shown to negatively modulate invasion and metastasis in bladder cancer by targeting the tumor promoter zinc finger E-box-binding homeobox 2 (ZEB2) (7). In addition, miR-454-3p inhibits BTG1 expression levels and inhibits cell cycle progression and metastasis in renal carcinoma cells (8). However, to the best of our knowledge, it is still unclear whether miR-454-3p is involved in the proliferation and invasion of ESCA cells.

Insulin-like growth factor $2 \mathrm{mRNA}$-binding protein 1 (IGF2BP1), a member of the RNA-binding IGF2BP protein family containing IGF2BP1, 2 and 3 (9), has been observed to be highly expressed in a variety of cancer types, including breast, ovarian, lung, liver, pancreatic and esophageal cancer (10), and functions as a tumor-promoting factor associated with metastasis and overall poor prognosis in colorectal 
carcinoma (11). The interaction between IGF2BP1 and its corresponding target mRNAs, such as actin, cytoplasmic 1, $c-M Y C, C D 44$ and MKI67 enable the modulation of cell proliferation and migration at the post-transcriptional level $(12,13)$. It was reported that the binding of IGF2BP1 to miRNA-140-5p results in the suppression of growth and metastasis of cervical cancer (14). However, whether this binding between IGF2BP1 and miR-454-3p plays important role in the progression of ESCA is still unclear.

Therefore, the present study investigated whether IGF2BP1 may be a promising direct target of miR-454-3p in ESCA, and explored how miR-454-3p-overexpression downregulated the proliferation, migration and invasion of ESCA cells by targeting IGF2BP1 in vitro. Additionally, the current study aimed to understand how miR-454-3p affected tumor growth and metastasis in an in vivo ESCA tumor mouse model.

\section{Materials and methods}

Collection of clinical tumor specimens. Patient information (including overall survival rate), ESCA tissues and matched adjacent normal tissues ( $5 \mathrm{~cm}$ from the tumor) were collected from patients with ESCA $(n=40)$. Tumor-Node-Metastasis (TNM) stage and invasion depth classification were determined as previously described (15). All patients provided written informed consent. The study was approved by The Ethics Committee of Affiliated Haian Hospital of Nantong University (Nantong, China). Surgically removed tissue samples by tumor resection were frozen in liquid nitrogen and stored at $-80^{\circ} \mathrm{C}$ until use.

Cell culture and transfections. The human esophageal epithelial cell (HEEC) line was obtained from ScienCell Research Laboratories, Inc. (cat. no. 2720), and four ESCA cell lines, EC9706, ECA109, TE-1 and TE-8, were obtained from the American Type Culture Collection. All cells were cultured in DMEM or RPMI1640 medium (both Gibco; Thermo Fisher Scientific, Inc.) with $10 \%$ of FBS (Gibco; Thermo Fisher Scientific, Inc., or Bio-Rad Laboratories, Inc.) and $1 \%$ penicillin $(100 \mu \mathrm{g} / \mathrm{ml}) /$ streptomycin $(100 \mathrm{U} / \mathrm{ml}) \mathrm{mix}$ at $37^{\circ} \mathrm{C}$ in an incubator under an atmosphere of $5 \% \mathrm{CO}_{2}$.

miR-454-3p mimics and negative control (miR-NC) were synthesized by Shanghai Gene Pharma Co., Ltd. and transfected into EC9706 and TE-1 cells using Lipofectamine ${ }^{\circledR}$ 2000 (Invitrogen; Thermo Fisher Scientific, Inc.). miR-454-3p inhibitors (miR-454-3p inh) and matched negative control (NC inh) were synthesized by Shanghai Gene Pharma Co., Ltd. and transfected into ECA109 and TE-8 cells using Lipofectamine ${ }^{\circledR} 2000$. After 24 h of incubation, further experiments were performed. For co-transfection, miR-454-3p mimics or miR-NC and short hairpin (sh)RNA-IGF2BP1 (sh-IGF2BP1) were co-transfected into TE-1 cells using Lipofectamine ${ }^{\circledR}$ 2000. miR-454-3p inh or NC inh and sh-IGF2BP1 were co-transfected into TE- 8 cells using Lipofectamine $^{\circledR} 2000$. After $24 \mathrm{~h}$ of incubation, further experiments were performed. The cDNA3.1-IGF2BP1 plasmid was constructed in-house by inserting the open reading frame of IGF2BP1 into a pcDNA3.1 plasmid (Thermo Fisher Scientific, Inc.) and then transfected into $293 \mathrm{~T}$ cells, as previously described (16).
$R N A$ extraction and quantitative reverse transcription $(R T-q)$ $P C R$. Total RNAs were extracted from patients' tissues and cultured cell lines using TRIzol ${ }^{\circledR}$ reagent (Thermo Fisher Scientific, Inc.) then converted into complementary DNA using a RevertAid RT Reverse Transcription kit (Thermo Fisher Scientific, Inc.), which was used according to the manufacturer's instructions. mRNA expression levels were quantified using qPCR and a Standard SYBR-Green RT-PCR kit (Takara Bio, Inc.) in accordance with the manufacturer's protocols. The thermocycling conditions were as follows: $50^{\circ} \mathrm{C}$ for $30 \mathrm{~min}$, followed by $95^{\circ} \mathrm{C}$ for $10 \mathrm{~min}$ and 40 cycles of $15 \mathrm{sec}$ at $95^{\circ} \mathrm{C}$ and $60 \mathrm{sec}$ at $60^{\circ} \mathrm{C}$. GAPDH was used as the control gene. All of the related miRNA reagents used were purchased from RiboBio Co., Ltd. The relative primers sequences were prepared (Sangon Biotech Co., Ltd.) as follows: miR-454-3p, Forward: 5'-ACCCTATCAATATTGTCTCTGC-3' and reverse: 5'-GCGAGCACAGAATTAATACGAC-3'; IGF2BP1, forward: 5'-CAAAGGAGCCGGAAAATTCAAAT-3' and reverse: 5'-CGTCTCACT CTCGGTGTTCA-3'; U6, forward, 5'-CTCGCTTCGGCAGCACA-3' and reverse: 5'-AACGCT TCACGAAYYYGCGT-3' and GAPDH, forward: 5'-AGACAC CATGGGGAAGGTGAA-3' and reverse: 5'-ATTGCTGAT GATCTTGAGGCTG-3'. The $2^{-\Delta \Delta C q}$ method (17) was used to calculate the relative expression levels of miR-454-3p expression levels after normalization to GAPDH small nuclear RNA.

Cell proliferation assay. Cell proliferation was analyzed using a Cell Counting Kit-8 (CCK-8) according to the manufacturer's protocol. CCK-8 was purchased from Dojindo Molecular Technologies, Inc. A total of 4x10 3 EC9706, TE-1, ECA109 and TE-8 cells were separately seeded in each well in 96-well plates. After incubation at $37^{\circ} \mathrm{C}$ for $2 \mathrm{~h}, 20 \mu \mathrm{l} \mathrm{CCK}-8$ was added to each well and incubated for $1 \mathrm{~h}$ at $37^{\circ} \mathrm{C}$. Viable cells were counted by measuring the optical density value using a microplate reader at the wavelength of $450 \mathrm{~nm}$. Each measurement was performed in triplicate in all experiments and the mean of the results was used to draw the growth curves.

Colony formation assay. A total of $5 \times 10^{2}$ cells (EC9706, TE-1, ECA109 and TE-8) were separately seeded in each well in 6-well plates. After incubation for 14 days in RPMI1640 medium containing $10 \% \mathrm{FBS}$ in a $37^{\circ} \mathrm{C}$ atmosphere of $5 \%$ $\mathrm{CO}_{2}$, the cells were fixed with $4 \%$ paraformaldehyde for $1 \mathrm{~h}$ at room temperature and stained using methanol and $0.1 \%$ crystal violet in $20 \%$ methanol for $15 \mathrm{~min}$ at room temperature. Finally, the cell numbers were counted manually under a light microscope (magnification, x40; Leica Biosystems).

Cell migration and invasion assays. Cell migration was analyzed using a wound healing assay. Firstly, ESCA cells (EC9706 and TE-1 cells transfected with miR-454-3p mimics or miR-NC, as well as ECA109 and TE-8 cells transfected with miR-454-3p inh or NC inh) were seeded in 6-well plates with $5 \times 10^{5}$ cells/well. After $24 \mathrm{~h}$ of incubation at $37^{\circ} \mathrm{C}$, the cell monolayer was removed using a micropipette tip and washed with phosphate-buffered saline (PBS). Then, a plastic scriber was used to scratch the wound and the cell monolayer was incubated at $37^{\circ} \mathrm{C}$ in serum-free medium for $48 \mathrm{~h}$. Finally, wound closure was observed under a light microscope (magnification, $\mathrm{x} 40$; Leica Biosystems). Triple detection was performed and 
the mean of results was calculated. Cell invasion was estimated using a Transwell assay. Firstly, $1 \times 10^{4}$ ESCA cells were seeded into the upper chamber coated with or without Matrigel (BD Biosciences) at $37^{\circ} \mathrm{C}$ for $24 \mathrm{~h}$. RPMI1640 medium containing $10 \%$ FBS, as a chemoattractant, was added into the bottom chamber. Then, the chamber was removed after $24 \mathrm{~h}$ incubation in a $37^{\circ} \mathrm{C}$ atmosphere of $5 \% \mathrm{CO}_{2}$, followed by gently removing the matrix glue and cells from the upper chamber with a wet cotton swab. Finally, cells were fixed using $4 \%$ paraformaldehyde for $30 \mathrm{~min}$ at room temperature and stained with crystal violet for $1 \mathrm{~h}$ at room temperature. After drying, five visual fields were selected under a light microscope (magnification, $\mathrm{x} 40)$ and the total cells were manually counted.

Bioinformatics analysis and luciferase reporter assay. Bioinformatics analysis was performed using miRanda (www.mirdb.org/), TargetScan (www.targetscan. org/vert_72/) and Pictar (pictar.mdc-berlin.de/) to identify potential target genes of miR-140-5p. To confirm the molecular interaction between miR-454-3p and IGF2BP1, a luciferase reporter assay was performed using human embryonic kidney 293T cells (Thermo Fisher Scientific, Inc.). The pmirGLO-IGF2BP1-3'UTR wild-type (IGF2BP1 3'UTR-WT) and pmirGLO-IGF2BP1-3'UTR mutant (IGF2BP1 3'UTR-MUT) were designed and obtained from Sangon Biotech Co., Ltd. 293T cells were seeded in 12-well plates with density of $1.5 \times 10^{5} /$ well. Then, $30 \mathrm{nM}$ miR-454-3p mimics or miR-NC were co-transfected with 300 ng DNA (IGF2BP1 3'UTR-WT or IGF2BP1 3'UTR-MUT) into 293T cells using Lipofectamine 2000 (Invitrogen; Thermo Fisher Scientific, Inc.) in accordance with the manufacturer's instructions. After transfection for $24 \mathrm{~h}$, the relative luciferase activity was assessed using a Dual-Luciferase Reporter Assay system (Promega Corporation). Relative firefly luciferase activity was compared with Renilla luciferase activity.

Western blot analysis. RIPA lysis buffer (9800; Cell Signaling Technology, Inc.) was used to lyse and extract total protein from all ESCA cell lines and patient tissues. After centrifugation at $16,128 \mathrm{x} \mathrm{g}$ for $10 \mathrm{~min}$ at $4^{\circ} \mathrm{C}$, protein concentration was determined used a BCA protein assay and proteins $(20 \mathrm{ng} / \mu \mathrm{l}$; $4 \mu \mathrm{l} /$ lane) were separated via $10 \%$ SDS-PAGE. Subsequently, obtained samples were transferred to polyvinylidene fluoride (PVDF) membranes and blocked with $5 \%$ milk for $1 \mathrm{~h}$ at $37^{\circ} \mathrm{C}$. Next, incubating the PVDF membrane with anti-IGF2BP1 (cat. no. sc-166344; 1:100), anti-GAPDH (cat. no. sc-47724; 1:1,000), anti-phosphorylated (p)-AKT (cat. no. sc-101629; 1:2,000)/t-AKT (cat. no. sc-81434; 1:2,000), anti-p-GSK3 $\beta$ (cat. no. sc-81496; 1:2,000)/t-GSK3 $\beta$ (cat. no. sc-7291; 1:2,000) and anti-p-ERK1/2 (cat. no. sc-136521; 1:2,000)/t-ERK1/2 (cat. no. sc-135900; 1:2,000) antibodies (all Santa Cruz Biotechnology, Inc.) at $37^{\circ} \mathrm{C}$ for $2 \mathrm{~h}$. Then, PVDF membranes were washed 3-5 times with $1 \mathrm{X}$ TBS-Tween buffer (1\% Tween-20) and co-incubated with HRP-conjugated anti-rabbit secondary antibodies (cat. no. 7074; 1:5,000; Cell Signaling Technology, Inc.) for $1 \mathrm{~h}$ at room temperature. ECL Western Blotting Detection Reagents were purchased from Cytiva and used to detect the visualized immunocomplexes. ImagePro software 6.0 (Media Cybernetics, Inc.) was used to calculate the intensity of each blots.
Immunohistochemistry (IHC) assay. Sections were fixed in $4 \%$ formaldehyde at room temperature for $24 \mathrm{~h}$ and embedded into paraffin. Paraffin-embedded sections (3- $\mu$ m-thick) were immersed in xylene solution to dewax for $2 \mathrm{~h}$ at room temperature, and in $95 \%$ ethanol solution to gradient rehydration. Then, $3 \%$ deionized water with hydrogen peroxide was used for quenching. After recovering the antigens and blocking with $10 \%$ fetal bovine serum (cat. no. 26140087; Gibco; Thermo Fisher Scientific, Inc.) in PBS at $37^{\circ} \mathrm{C}$ for $1 \mathrm{~h}$, the sections were incubated with anti-IGF2BP1 antibody (1:100; cat. no. HPA021367; Sigma-Aldrich; Merck KGaA) overnight at $4^{\circ} \mathrm{C}$, and subsequently incubated with HRP-conjugated secondary antibody (cat. no. 7074; 1:5,000; Cell Signaling Technology, Inc.) for $30 \mathrm{~min}$ at $37^{\circ} \mathrm{C}$. Finally, the sections were stained with DAB for $1 \mathrm{~h}$ at $37^{\circ} \mathrm{C}$, then counterstained with hematoxylin for $1 \mathrm{~h}$ at $37^{\circ} \mathrm{C}$. The section were observed using confocal microscopy at a magnification of x10.

Flow cytometry analysis for cell apoptosis. Cell apoptosis was analyzed using a Dead Cell Apoptosis kit (cat. no. V13242; Invitrogen; Thermo Fisher Scientific, Inc.). Four transfected cell lines (EC9706, TE-1, ECA109 and TE-8) were separately planted into 6-well plates with a density of $8 \times 10^{4}$ in each well. After $48 \mathrm{~h}$ incubation at $37^{\circ} \mathrm{C}$, the cells were harvested and subsequently re-suspended in $500 \mu \mathrm{l}$ PBS buffer and stained with $5 \mu$ 1 Alexa Fluor 488-annexin $\mathrm{V}$ and $1 \mu \mathrm{l}$ PI solution $(100 \mu \mathrm{g} / \mathrm{ml})$ in each $100 \mu \mathrm{l}$ of cell suspension at room temperature for $15 \mathrm{~min}$. Apoptosis was measured using an Attune NxT flow cytometer (Thermo Fisher Scientific, Inc.) and analyzed with the Attune NxT software v2.6 (Thermo Fisher Scientific, Inc.).

In vivo tumor xenograft in nude mice. A total of 20 four-week old BALB/c-nude mice (male, 20-22 g) were purchased from the Shanghai Laboratory Animal Center. There were five mice in each group. All mice had access to food and water ad libitum, and the temperature in the cages was maintained at $24 \pm 1^{\circ} \mathrm{C}$ with a $12 / 12 \mathrm{~h}$ light/dark cycle and $40-50 \%$ humidity. All the procedures involved in experimental animals were approved by The Ethics Committee of Affiliated Haian Hospital of Nantong University. All the animal welfare considerations were according to the international animal experiment standard. Next, $1 \times 10^{7}$ ESCA cells (TE-1 cell line) in $0.2 \mathrm{ml}$ PBS buffer were subcutaneously injected in the stomach of each mouse. Then the mice were injected intraperitoneally with agomiR-miR-454-3p (equal to miR-454-3p mimics) or agomiR-NC (equal to miR-NC) every 7 days for 4 weeks. No mice died during the experiment. After successfully obtaining a stable mouse model, the tumor size and volume [volume $\left(\mathrm{mm}^{3}\right)=$ width $^{2}\left(\mathrm{~mm}^{2}\right)$ x length $\left.(\mathrm{mm}) \div 2\right]$ was measured every 3 days until the diameter of tumors were $\sim 20 \mathrm{~mm}$ in control group (agomiR-NC treatment group). Then the mice were euthanized by intravenous injection with $200 \mathrm{mg} / \mathrm{kg}$ pentobarbital after 4 weeks of tumor growth, followed by cervical dislocation. Finally, esophageal tissues were isolated and used for the aforementioned tissue analyses.

Statistical analysis. All experiments were performed at least three times and mean values were calculated. SPSS version 19.0 (IBM Corp.) software was used to analyze the data, 
which was presented as the mean \pm SD. Kaplan-Meier analysis with log-rank test was performed using GraphPad Prism 8.0 (GraphPad Software, Inc.) and was used to determine the association between miR-454-3p expression and patient survival rates. Spearman's correlation analysis was performed to identify the correlation between miR-454-3p and IGF2BP1 expression. The difference between groups was tested by unpaired or paired (tumor vs. normal tissues) Student's t-test or one-way ANOVA with Tukey's post hoc test. In addition, t-tests were used to determine the associations between miR-454-3p expression and the clinicopathological parameters. $\mathrm{P}<0.05$ was considered to indicate a statistically significant difference.

\section{Results}

Low miR-454-3p expression in human ESCA tissues and association with patient survival. In the present study, the association between miR-454-3p and the pathogenesis of ESCA and patient survival were investigated. Histological staining was used for the isolated ESCA tissues and normal tissues from 40 patients with ESCA. Two high-power visual fields (magnification, x200 and x400) were selected. It was observed that compared with normal tissues, ESCA cells had larger volume and were pleomorphic, varying greatly in size and shape, and the ratio of nucleus to cytoplasm in tumor cells was different from that of normal cells (Fig. 1A). In addition, the mRNA expression of miR-454-3p was significantly downregulated in tumor tissues compared with that in adjacent normal tissues (Fig. 1B; $\mathrm{P}<0.001$ ). Subsequently, the association between clinicopathological characteristics and different miR-454-3p expression in patients with ESCA were analyzed. The results showed that either low or high expression of miR-454-3p had no association with the characteristics of patients' age, sex and cellular differentiation. However, miR-454-3p expression was significantly associated with Tumor-Node-Metastasis (TNM) stage $(\mathrm{P}=0.014)$, invasion depth classification $(\mathrm{P}=0.026)$ and lymph node metastasis $(\mathrm{P}=0.029)$ (all Table I). Additionally, the association between miR-454-3p expression and patients' survival rates was analyzed. Kaplan-Meier analysis demonstrated that patients with high miR-454-3p expression $(n=17)$ had improved survival rates compared with patients with low expression $(n=23)$; this indicated that miR-454-3p might be a tumor suppressor for ESCA (Fig. 1C). The expression differences of miR-454-3p between normal human esophageal epithelial cells and four ESCA cells (EC9706, ECA109, TE-1 and TE-8) were further evaluated using RT-qPCR. Consistent with previous results, the expression levels of miR-454-3p in normal HEECs were significantly higher compared with those in four ESCA cell lines (Fig. 1D).

Overexpression of miR-454-3p suppresses ESCA cell proliferation and promotes apoptosis in vitro. To investigate the effect of miR-454-3p on the proliferation and apoptosis of ESCA cells, EC9706, ECA109, TE-1 and TE-8 cells were stably transfected with either miR-454-3p mimics or inhibitors. RT-qPCR analysis revealed that EC9706 and TE-1 cells that transfected with miR-454-3p mimics displayed higher expression of miR-454-3p compared with that of miR-NC-transfected cells, and that ECA109 and TE-8 cells treated with miR-454-3p inhibitors possessed lower expression levels of miR-454-3p compared with those of NC inh-transfected cells (Fig. 2A). In addition, the effect of miR-454-3p on the cell proliferation was detected using a CCK-8 and colony formation assay. The results of the CCK-8 assay indicated that the cell proliferation rate in miR-454-3p mimics-transfected EC9706 and TE-1 cells was significantly decreased $(\mathrm{P}<0.05)$. Meanwhile, the cell proliferation rate of ECA109 and TE-8 cells treated with miR-454-3p inhibitors was significantly increased $(\mathrm{P}<0.05)$ (both Fig. 2B). The colony formation assay indicated that the number of colonies formed by EC9706 and TE-1 cells transfected with miR-454-3p mimics and ECA109 and TE-8 cells transfected with NC inhibitors were less compared with those in the control groups (Fig. 2C). Therefore, it was speculated that miR-454-3p negatively regulated cell proliferation in ESCA. However, whether miR-454-3p affected the apoptosis of ESCA cells needed to be verified. Flow cytometry was performed to detect the rate of apoptosis in EC9706, TE-1, ECA109 and TE-8 cells transfected with miR-454-3p mimics or miR-454 inhibitors (Fig. 2D). The data demonstrated that miR-454-3p-overexpression significantly promoted apoptosis. In conclusion, these results showed that miR-454-3p inhibited the proliferation of ESCA cells.

miR-454-3p inhibits the migration and invasion in ESCA cells in vitro. To identify the role of $\mathrm{miR}-454-3 \mathrm{p}$ in the migration and invasion of ESCA cells, wound healing and Matrigel assays were conducted. The wound healing assay revealed that the wound width of EC9706 and TE-1 cells transfected with miR-454-3p mimics was significantly wider compared with that of miR-NC-transfected cells. This was the opposite to the results of ECA109 and TE-8 cells transfected with miR-454-3p inhibitors/NC inhibitors (Fig. 3A). These results demonstrated that miR-454-3p overexpression could inhibit migration of ESCA cells. Additionally, the Matrigel assay revealed the number of invasive EC9706 and TE-1 cells treated with miR-454-3p mimics were fewer compared with the number of invasive EC9706 and TE-1 cells transfected with miR-NC. Conversely, the number of invasive EC9706 and TE- 1 cells treated with miR-454-3p inhibitors were higher compared with the number of invasive ECA109 and TE-8 cells transfected with NC-inh (Fig. 3B). These results illustrated that overexpression of miR-454-3p could significantly suppress the invasion and migration of ESCA cells. Taken together, these data suggested that miR-454-3p functions as an inhibitor of the migration and invasion of ESCA cells.

IGF $2 B P 1$ is the direct target of miR-454-3p in ESCA. According to bioinformatics predication with miRanda, TargetScan and Pictar, the IGF2BP1 gene was identified as the target gene of miR-140-5p (Fig. 4A). Then luciferase reporter assays were used to detect the binding affinity of miR-454-3p to the wild-type 3'UTR of IGF2BP1 in 293T cells. The results showed that the luciferase activity in miR-454-3p mimics-transfected $293 \mathrm{~T}$ cells was significantly decreased. Notably, miR-454-3p-overexpression did not change the luciferase activity of mutant IGF2BP1 3'UTR (Fig. 4B). Therefore, it was speculated that IGF2BP1 3'UTR-WT was the direct target of miR-454-3p. To explore how miR-454-3p regulated the expression of IGF2BP1, western blot analysis was 
A

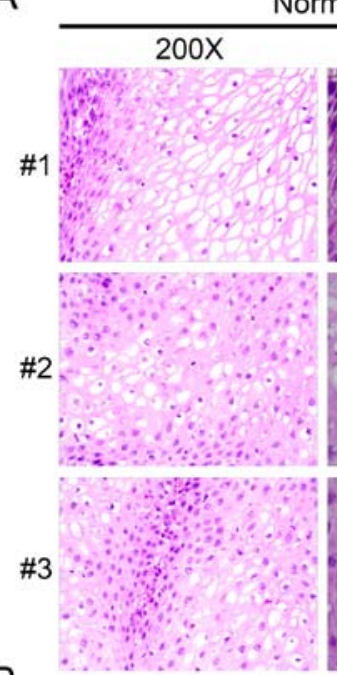

B

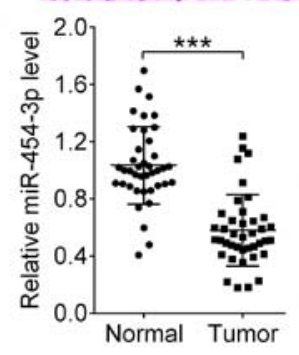

C

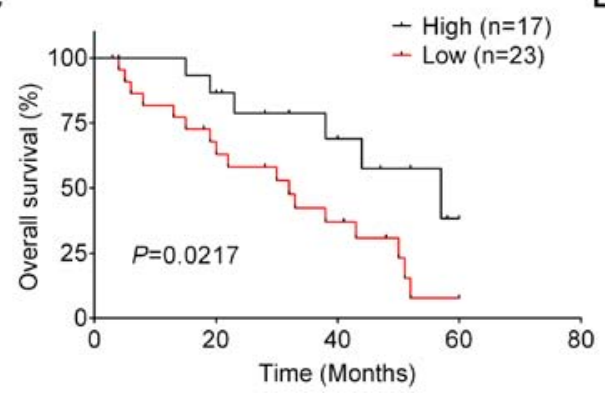

Normal
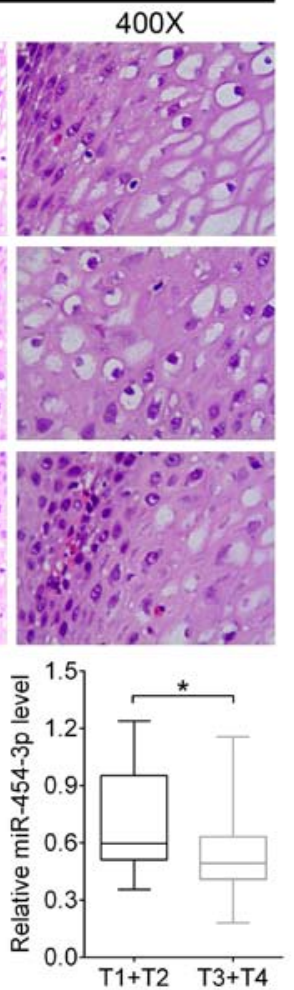
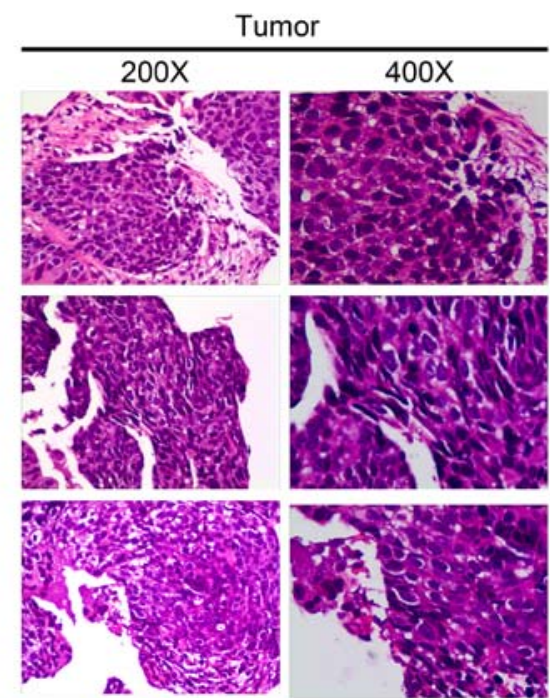

A.
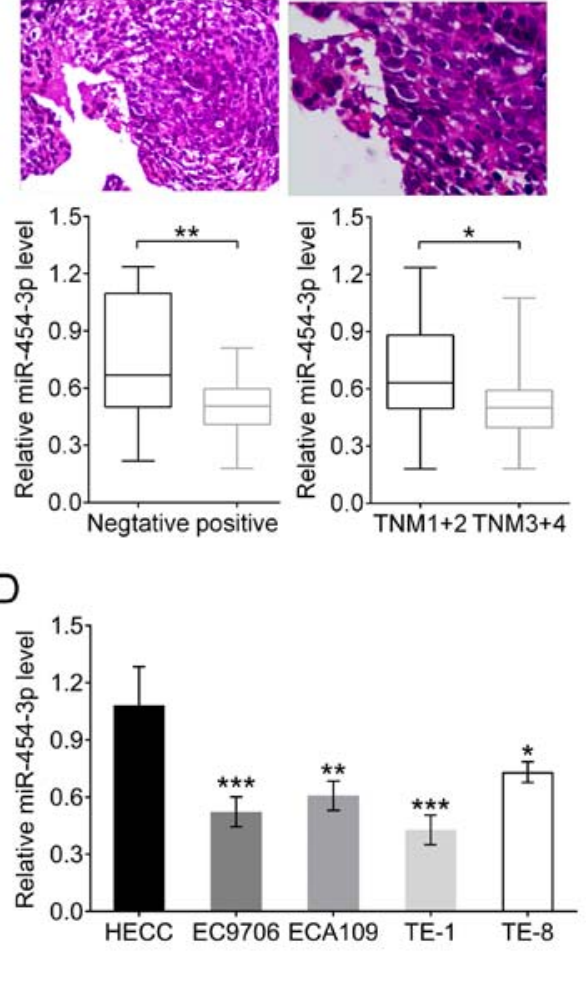

Figure 1. miR-454-3p expression is low in ESCA tissues and cells and associated with the overall survival of patients. (A) Representative images of hematoxylin and eosin stained ESCA tissues and matched adjacent normal tissues. (B) RT-qPCR was used to analyze the expression difference of miR-454-3p between tumor tissues and adjacent normal tissues in 40 patients as well as the association between various clinicopathological parameters, including invasive depth, lymph node metastasis and TNM stages, and miR-454-3p expression. (C) Overall survival analysis of miR-454-3p expression in patients with ESCA. (D) RT-qPCR was used to analyze the expression difference of miR-454-3p in normal human esophageal epithelial cells and four ESCA cell lines (EC9706, ECA109, TE-1 and TE-8). All of the aforementioned results are presented as mean $\pm \mathrm{SD} .{ }^{*} \mathrm{P}<0.05,{ }^{* * *} \mathrm{P}<0.01$ and ${ }^{* * *} \mathrm{P}<0.001$. miR, microRNA; ESCA, esophageal cancer; RT-qPCR, reverse transcription-quantitative PCR; TNM, Tumor-Node-Metastasis.

performed. The results showed that the miR-454-3p mimics transfection group had significantly decreased expression of IGF2BP1 both in EC9706 and TE-1 cells. Conversely, EC109 and TE-8 cells transfected with miR-454-3p inhibitors had increased expression of IGF2BP1. Thus, these data demonstrated that miR-454-3p negatively regulated the expression of IGF2BP1 (Fig. 4C). Additionally, the expression differences of IGF2BP1 between tumor tissues and normal adjacent tissues in five patients with ESCA were explored using western blotting. It was reported that the protein expression of IGF2BP1 in tumor tissue was significantly higher compared with those in normal tissues, which indicated that upregulated IGF2BP1 promoted the development of ECSA (Fig. 4D). RT-qPCR analysis reported that the mRNA expression of $I G F 2 B P I$ was higher in tumor tissues compared with that in adjacent normal tissues, which was consistent with previous results (Fig. 4E). The data showed a significant inverse correlation between IGF2BP1 and miR-454-3p expression in tumor tissues using Spearman's correlation analysis $(\mathrm{r}=0.7243, \mathrm{P}<0.001$; Fig. $4 \mathrm{~F})$. Taken together, these results demonstrated that IGF2BP1 is the downstream target gene of miR-454-3p and that downregulated miR-454-3p leads to the upregulation of IGF2BP1 in ESCA.

miR-454-3p suppresses ESCA cell proliferation, migration and apoptosis by targeting IGF $2 B P 1$ in vitro. To explore whether the tumor inhibitor function of miR-454-3p is mediated by IGF2BP1, TE- 1 and TE- 8 cells were stably transfected with IGF2BP1, miR-454-3p or their inhibitors, respectively. 
Table I. The correlation between clinicopathological characteristics and miR-454-3p expression in ESCA patients ( $\mathrm{n}=40$ ).

\begin{tabular}{|c|c|c|c|}
\hline Characteristic & Value, $\%$ & miR-454-3p expression & P-value \\
\hline \multicolumn{4}{|l|}{ Age, years } \\
\hline$\geq 60$ & 24 & $5.45 \pm 1.03$ & \multirow[t]{2}{*}{0.821} \\
\hline$<60$ & 16 & $5.53 \pm 1.17$ & \\
\hline \multicolumn{4}{|l|}{ Sex } \\
\hline Male & 23 & $5.31 \pm 1.07$ & \multirow[t]{2}{*}{0.248} \\
\hline Female & 17 & $5.71 \pm 1.06$ & \\
\hline \multicolumn{4}{|l|}{ Differentiation } \\
\hline Well/Moderate & 18 & $5.36 \pm 1.22$ & \multirow[t]{2}{*}{0.551} \\
\hline Poor & 22 & $5.57 \pm 0.99$ & \\
\hline \multicolumn{4}{|l|}{ TNM stage } \\
\hline Stage I/II & 16 & $4.98 \pm 1.04$ & \multirow[t]{2}{*}{$0.014^{\mathrm{a}}$} \\
\hline Stage III/IV & 24 & $5.81 \pm 0.97$ & \\
\hline \multicolumn{4}{|l|}{ Invasive depth } \\
\hline $\mathrm{T} 1 / \mathrm{T} 2$ & 14 & $4.97+0.96$ & \multirow[t]{2}{*}{$0.026^{\mathrm{a}}$} \\
\hline T3/T4 & 26 & $5.75 \pm 1.04$ & \\
\hline \multicolumn{4}{|c|}{ Lymph node metastasis } \\
\hline Negative & 13 & $5.09 \pm 1.09$ & \multirow[t]{2}{*}{$0.029^{\mathrm{a}}$} \\
\hline Positive & 27 & $5.67 \pm 1.03$ & \\
\hline
\end{tabular}

${ }^{\mathrm{a}} \mathrm{P}<0.05$. TNM, Tumor-Node-Metastasis.

The CCK-8 and colony formation assays revealed that transfection with miR-454-3p mimics significantly inhibited the proliferation of both TE-1 and TE-8 cells, but this inhibition was reversed by IGF2BP1-overexpression. (Fig. 5A and B). Hence, it was hypothesized that miR-454-3p inhibited proliferation by targeting IGF2BP1 in ESCA cells. Apoptosis was detected using flow cytometry analysis of stably transfected TE-1 and TE- 8 cells, and the results showed that miR-454-3p-overexpression promoted apoptosis and IGF2BP1-overexpression suppressed the apoptosis (Fig. 5C). These results suggested that miR-454-3p may function as a tumor suppressor by targeting IGF2BP1. The wound healing assay showed that high expression of miR-454-3p maintained a significantly wider wound width and this results was reversed by IGF2BP1-overexpression in both TE-1 and TE- 8 cells. These results suggested that miR-454-3p-overexpression inhibited cell migration by targeting ICF2BP1 (Figs. 5D and S1). Additionally, the Transwell assay demonstrated that miR-454-3p-overexpression significantly decreased the invasive cell number and that this effect could be reversed by additional IGF2BP1 transfection in both TE-1 and TE- 8 cells (Fig. 5E). Therefore, it was revealed that miR-140-5p suppressed ESCA cell migration and invasion in vitro by targeting ICF2BP1. A previous study reported the inhibition effect of miR-9 on the ERK and AKT pathways was mediated by targeting IGF2BP1 in hepatocellular carcinoma (17), thus the present study explored whether miR-454-3p acted as a suppressor of these pathways through targeting IGF2BP1 in ESCA. Western blot analysis revealed a significant downregulation of phosphorylated proteins, such as p-AKT, p-GSK3 and p-ERK1/2, in TE-1 cells that were transfected with miR-454-3p mimics, and this decrease was recovered by IGF2BP1-overexpression. Moreover, the expression levels of these phosphorylated proteins were increased by transfection with miR-454-3p inhibitors in TE-8 cells, and this tendency was reversed by IGF2BP1-overexpression (Fig. 5F). Therefore, it was speculated that miR-454-3p suppressed the ERK and AKT pathways through targeting IGF2BP1 in ESCA. In a summary, these results showed that miR-454-3p suppressed ESCA cell proliferation, migration and apoptosis by targeting IGF2BP1 via the ERK and AKT pathways in vitro.

Studying the suppression of miR-140-5p on tumor proliferation and metastasis in vivo. In addition to in vitro studies, the in vivo suppressive effects of miR-140-5p on tumor proliferation and metastasis were investigated using a xenograft tumor mouse model. RT-qPCR analysis reported that the relative expression levels of miR-454-3p were significantly higher in TE-1-angmiR-miR-454-3p mice compared with the control $(\mathrm{P}<0.001$; Fig. $6 \mathrm{~A})$, which demonstrated that the xenograft tumor mouse model was successfully constructed. Additionally, compared with TE-1-agomiR-NC mice, the tumor size, weight and volume were significantly decreased in TE-1-angmiR-miR-454-3p mice compared with the control (Fig. 6B), which indicated that miR-454-3p-overexpression could inhibit the tumor growth in ESCA. After raising for 4 weeks, the mice were sacrificed and the esophagus was isolated. At the time of sacrifice, compared to initial treatment, the weight of each mouse in the agomiR-NC group was $24.2,23.1,22.3,22.2$ and $21.8 \mathrm{~g}$, while, compared to initial treatment, the weight of each mouse in the agomiR-454 group 


\section{A \\ B}
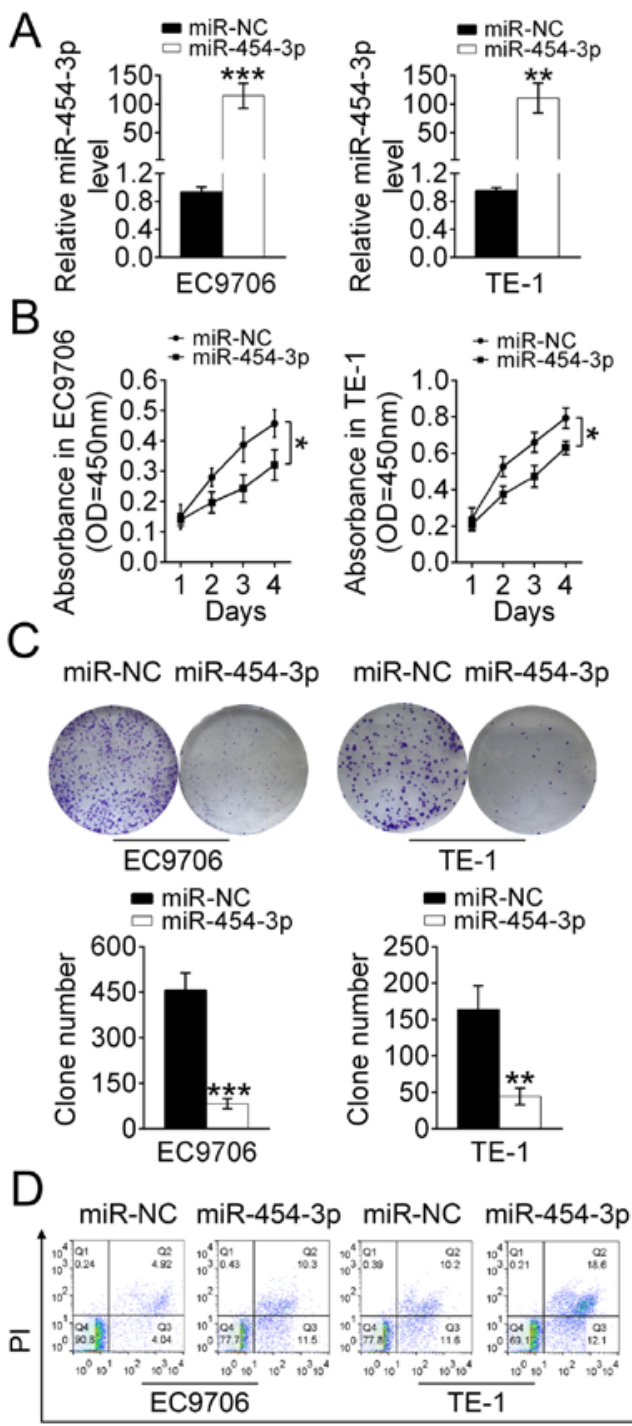

miR-NC miR-454-3p
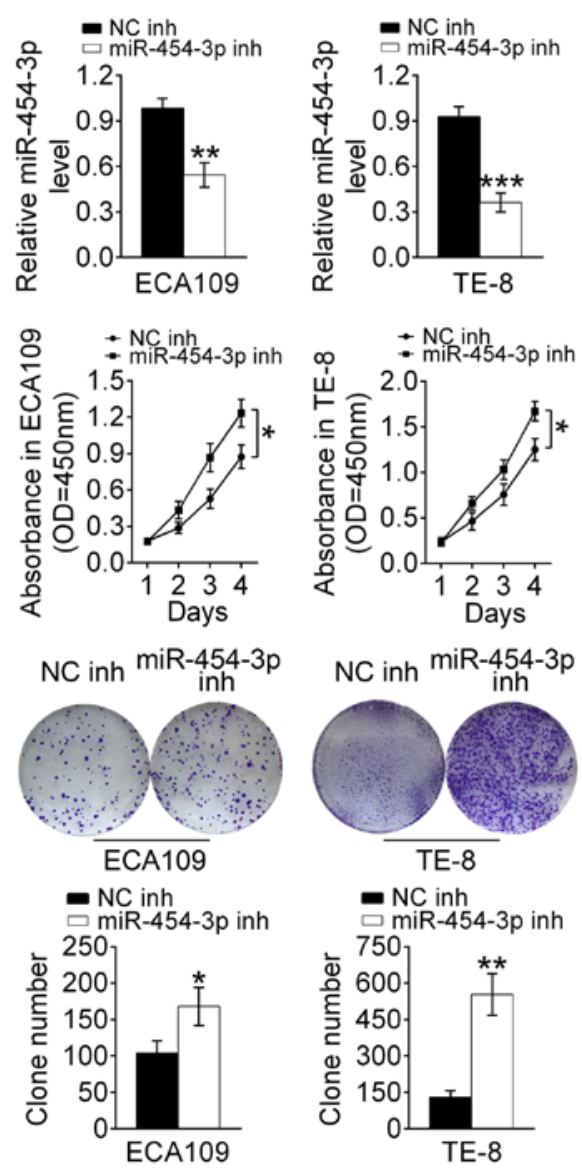

- NC inh
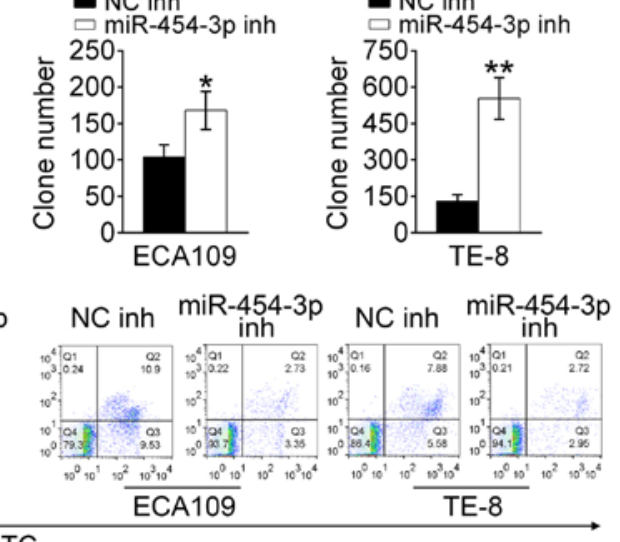
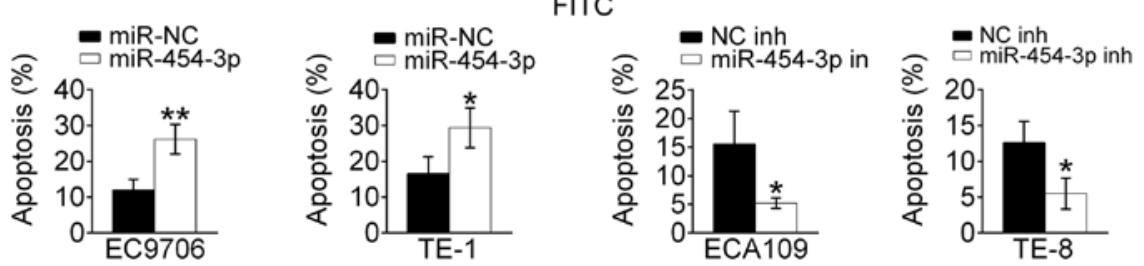

Figure 2. Overexpression of miR-454-3p suppresses the proliferation and promotes the apoptosis of ESCA cells in vitro. (A) Reverse transcription-quantitative PCR was used to analyze the relative expression levels of miR-454-3p in EC9706 and TE-1 cells transfected with miR-454-3p mimics/miR-NC as well as in ECA109 and TE-8 cells transfected with miR-454-3p inh/NC inhibitors (NC inh). (B) A Cell Counting Kit-8 assay was used to evaluate the proliferation of EC9706, TE-1, ECA109 and TE-8 cells transfected with miR-454-3p plasmid/NC mimics or miR-454 inhs/NC inh for 1, 2, 3 and 4 days. (C) Colony formation assays demonstrated the effect of miR-454-3p on the proliferation of EC9706, TE-1, ECA109 and TE-8 cells transfected with miR-454-3p mimics/miR-NC or miR-454-3p inh/NC inh and the colony number was quantified after transfection. (D) The apoptotic EC9706, TE-1, ECA109 and TE-8 cells transfected with miR-454-3p mimics/miR-NC or miR-454-3p inh/NC inh were determined using flow cytometry analysis. Results are presented as mean \pm SD. "P<0.05, ${ }^{* *} \mathrm{P}<0.01$ and ${ }^{* * *} \mathrm{P}<0.001$ vs. respective control. miR, microRNA; ESCA, esophageal cancer; NC, negative control; inh, inhibitor; miR-NC, negative control mimic.

was $19.7,16.4,17.9,18.2$ and $20.6 \mathrm{~g}$. Additionally, the percentages of the tumor weight/animal body weight in each mouse were calculated. For the agomiR-NC mice group, the percentages of the tumor weight/animal body weight in each mouse were 7.1, 5.8, 7.1, 8.2 and 8.5\%. For the agomiR-454 group, the data were $0.7,0.9,0.7,1.0$ and 1.0. At the time of sacrifice, compared with the control group (not initial treatment) due to cachexia/ascites, the weight increase in each mouse in the agomiR-NC group was $+2.52,+2.01,+2.24,+2.15$ and
$+1.63 \mathrm{~g}$, and no weight loss was observed in the agomiR-NC group. However, compared with the control group (not initial treatment) due to cachexia/ascites, the weight loss in each mouse in the agomiR-454 group was-2.11, -2.30, -1.97, -2.01 and $-1.32 \mathrm{~g}$, and no weight increase was observed in the agomiR-454 group.

IHC staining analysis revealed that isolated ESCA tumor issues from TE-1-angmiR-miR-454-3p mice exhibited higher expression of cleaved caspase- 3 and E-cadherin as well as 

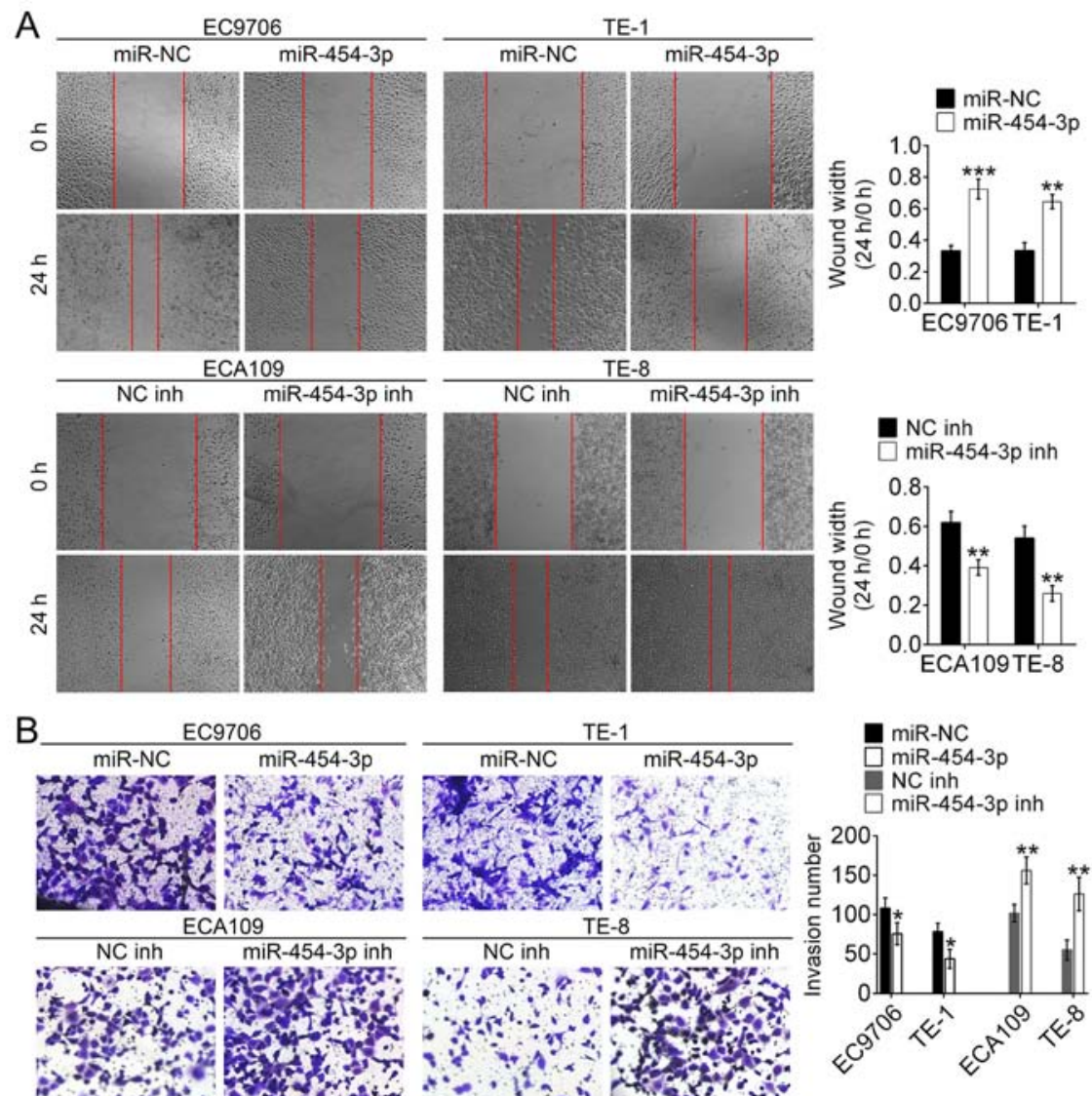

Figure 3. miR-454-3p downregulates the migration and invasion of ESCA cells in vitro. (A) Wound healing assays examined the cell migration in miR-454-3p mimics/miR-NC-transfected EC9706 and TE-1 cells as well as miR-454-3p inhibitors/NC inh-transfected ECA109 and TE-8 cells. (B) Transwell assays determined the number of invasive EC9706 and TE-1 cells treated with miR-454-3p mimics/miR-NC and ECA109 and TE-8 cells transfected with miR-454-3p inh/ $\mathrm{NC}$ inh. Results are presented as mean $\pm \mathrm{SD} .{ }^{*} \mathrm{P}<0.05,{ }^{* *} \mathrm{P}<0.01$ and ${ }^{* * *} \mathrm{P}<0.001$ vs. respective control. miR, microRNA; ESCA, esophageal cancer; NC, negative control; inh, inhibitor; miR-NC, negative control mimic.

A

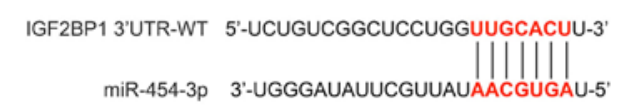
IGF2BP1 3'UTR-MUT 5'-UCUGUCGGCUCCUGGAACGUGAU-3'

C
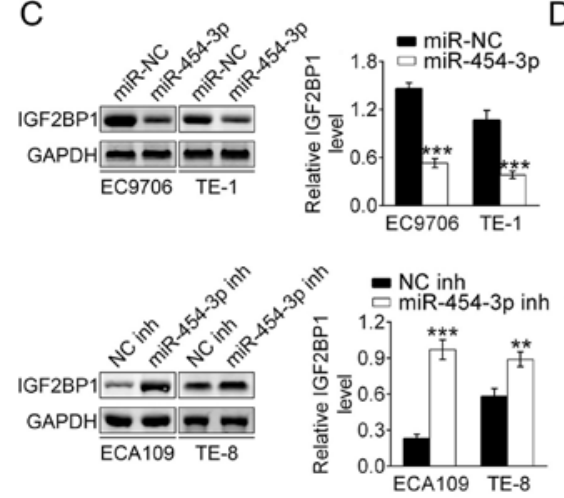

$\mathrm{D}$

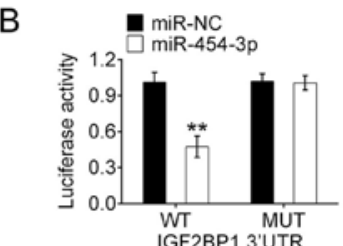

$\begin{array}{lllllllllll}\mathrm{N} 1 & \mathrm{~T} 1 & \mathrm{~N} 2 & \mathrm{~T} 2 & \mathrm{~N} 3 & \mathrm{~T} 3 & \mathrm{~N} 4 & \mathrm{~T} 4 & \mathrm{~N} 5 & \mathrm{~T} 5\end{array}$
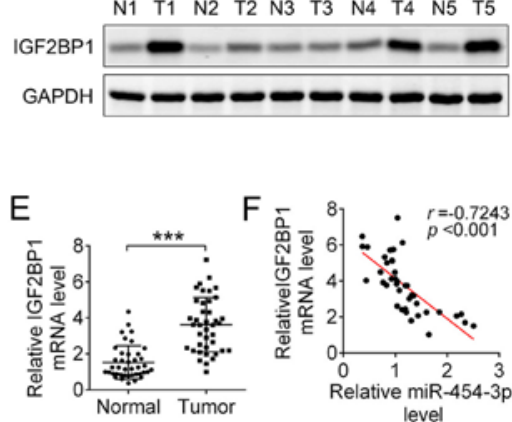

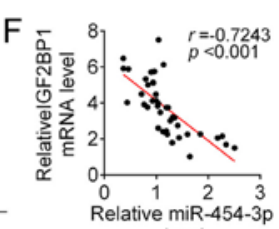

level

Figure 4. IGF2BP1 is the direct target of miR-454-3p. (A) The sequences of miR-454 binding sites complemented with the IGF2BP1 3'-UTR (base position of 4048-4054). IGF2BP1 3'-UTR-WT represents the entire 3'UTR sequences of WT IGF2BP1, IGF2BP1 3'-UTR-MUT represents the binding sites were mutated. (B) Luciferase reporter assays were performed in 293T cells to detect the binding affinity of miR-454-3p to the IGF2BP1 3'UTR-WT or MUT. (C) Western blotting was used to analyze how the overexpression or inhibition of miR-454-3p in EC9706, TE-1 ECA109 and TE-8 cells affected the IGF2BP1 protein levels. (D) Western blotting revealed the expression differences of IGF2BP1 protein levels between tumor tissues and normal adjacent tissues in five patients. (E) Reverse transcription-quantitative PCR demonstrated the relative IGF2BP1 mRNA expression levels in tumor tissues or normal adjacent tissues from patients with ESCA $(\mathrm{n}=40)$. (F) Pearson correlation test was used to evaluate the correlation between mRNA levels of IGF2BP1 and miR-454-3p expression in tumor tissues from 40 patients with esophageal cancer $(\mathrm{r}=-0.7243 ; \mathrm{P}<0.001)$. Results are presented as mean $\pm \mathrm{SD}$. ${ }^{* *} \mathrm{P}<0.01$ and ${ }^{* * * *} \mathrm{P}<0.001$. miR, microRNA; IGF2BP1, insulin-like growth factor 2 mRNA-binding protein 1; UTR, untranslated region; WT, wild-type; MUT, mutant; NC, negative control; inh, inhibitor. 


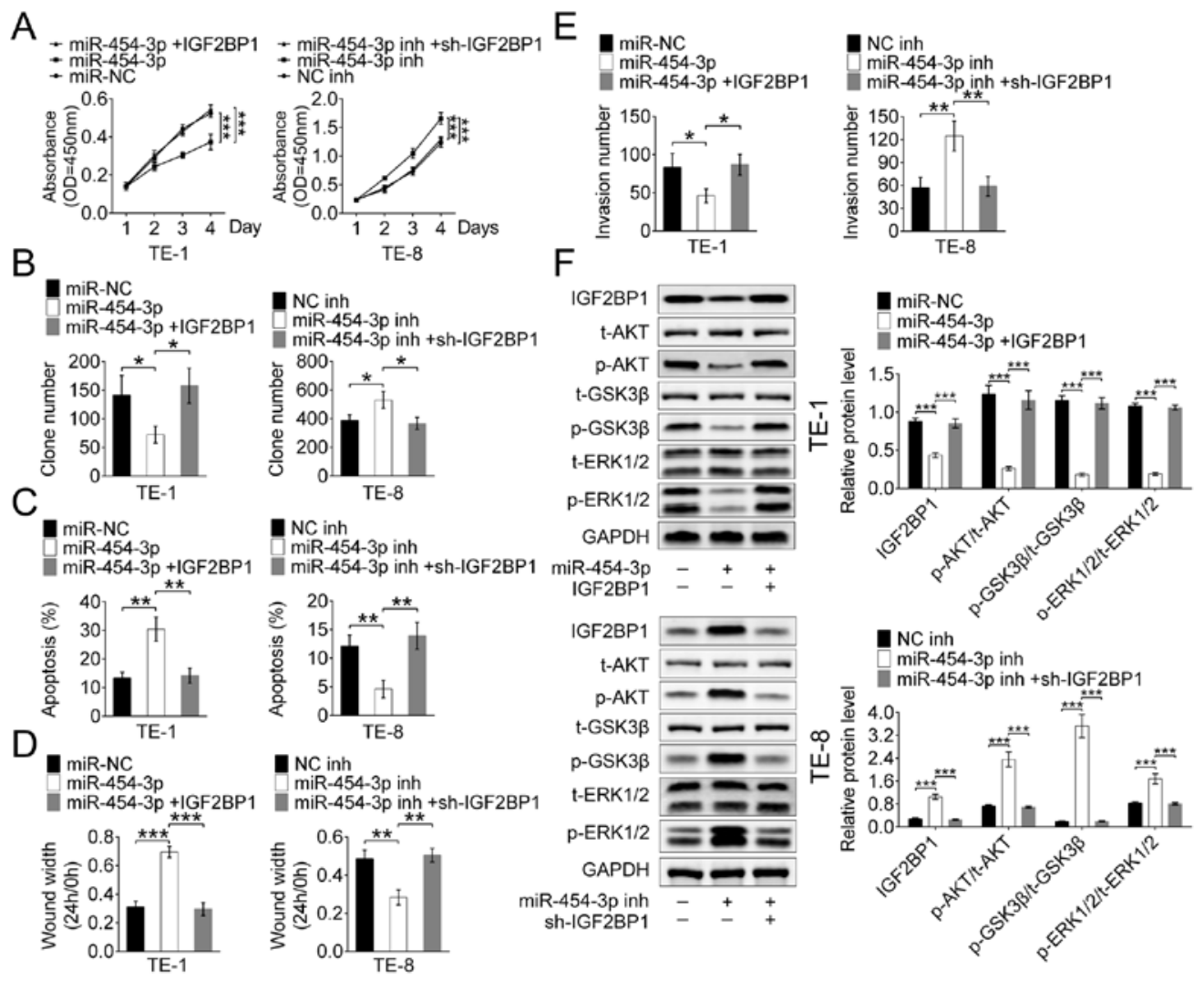

Figure 5. miR-454-3p inhibited IGF2BP1 expression via the ERK and P13K/AKT signaling pathways in vitro. (A) A Cell Counting Kit-8 assay and (B) colony formation assay were used to evaluate the proliferation in TE-1 and TE-8 cells transfected with miR-454-3p mimics IGF2BP1 and their inhibitors. (C) Flow cytometry was used to analyze the apoptosis TE-1 and TE-8 cells transfected with miR-454-3p mimics, IGF2BP1 or their inhibitors. (D) Wound healing and (E) Transwell assays were used to detected the cell migration and invasion of TE-1 and TE-8 cells transfected with miR-454-3p mimics, IGF2BP1 and their inhibitors. (F) Western blot analysis of the expression difference of related protein levels, including t-AKT, p-AKT, p-GSK3 $\beta, \mathrm{t}$-GSK3, p-ERK1/2 and t-ERK1/2, of the ERK and AKT signaling pathways in TE-1 and TE-8 cells transfected with miR-454-3p mimics, IGF2BP1 or their inhibitors. Results are presented as mean $\pm \mathrm{SD} .{ }^{*} \mathrm{P}<0.05,{ }^{* * *} \mathrm{P}<0.01$ and ${ }^{* * *} \mathrm{P}<0.001$. miR, microRNA; IGF2BP1, insulin-like growth factor 2 mRNA-binding protein 1; t-total; p-, phosphorylated.

lower expression of $\mathrm{Ki}-67$ and IGF2BP1 when compared with the TE-1-agomiR-NC mice. The results strongly illustrated miR-454-3p-overexpression could inhibit the tumor cell proliferation and invasion in vivo (Fig. 6C). It was then explored whether miR-454-3p could inhibit the ESCA cell proliferation, migration and apoptosis by targeting IGF2BP1 via ERK and AKT pathways in vivo. Western blot data demonstrated TE-1-angmiR-miR-454-3p mice could induce significantly lower expression of phosphorylated proteins, such as p-AKT, p-GSK3 and p-ERK1/2, which demonstrated that miR-454-3p suppressed the ERK and AKT pathways through targeting IGF2BP1 in vivo (Fig. 6D). Taken together, the xenograft tumor mouse model studies demonstrated miR-454-3p-overexpression served as an inhibitor for ESCA tumor proliferation and metastasis in vivo.

\section{Discussion}

ESCA is one of the most common tumors and a notable threat to human health (18). Despite traditional therapies having improved greatly, the prognosis and 5-year survival rates of patients with ESCAs remain poor (19). Due to the lack of obvious early symptoms and precise tumor markers, the vast majority of patients with ESCA are diagnosed at a late stage before treatment (20). Therefore, to improve the treatment
ESCA, our understanding of its pathogenesis needs to improve to allowed the identification of effective therapeutic targets.

Several studies have reported that miRNAs are involved in promoting or suppressing tumor initiation and progression in various human malignancies, such as cervical cancer (21), gastric cancer (22), ESCA (23) and hepatocellular carcinoma (24). Therefore, exploring the functional targets of miRNAs as well as illustrating the molecular mechanism underlying their function is a promising strategy for the cancer treatment.

miR-454-3p, a widely studied miRNA, was the focus of the present study as it participates in tumorigenesis. For example, abnormally expressed miR-454-3p is involved in regulating tumor progression in bladder cancer (7), renal carcinoma (8), chondrosarcoma (25) and non-small cell lung cancer adenocarcinoma (26). In the current study, by analyzing the association between clinicopathological characteristics and miR-454-3p expression, it was revealed that $\mathrm{miR}-454-3 \mathrm{p}$ was associated with the prognosis of patients with esophageal cancer. Therefore, it was demonstrated that miR-454-3p functions in the initiation and progression of ESCA. It is known that the molecular pathogenesis of miRNAs in modulating the metastasis of different types of cancer are quite different. For example, one study reported that miR-454-3p suppressed tumor cell growth and invasion by interacting with ZEB2 in bladder cancer (7), 
A

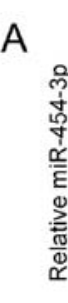

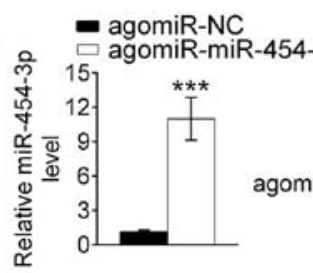

C

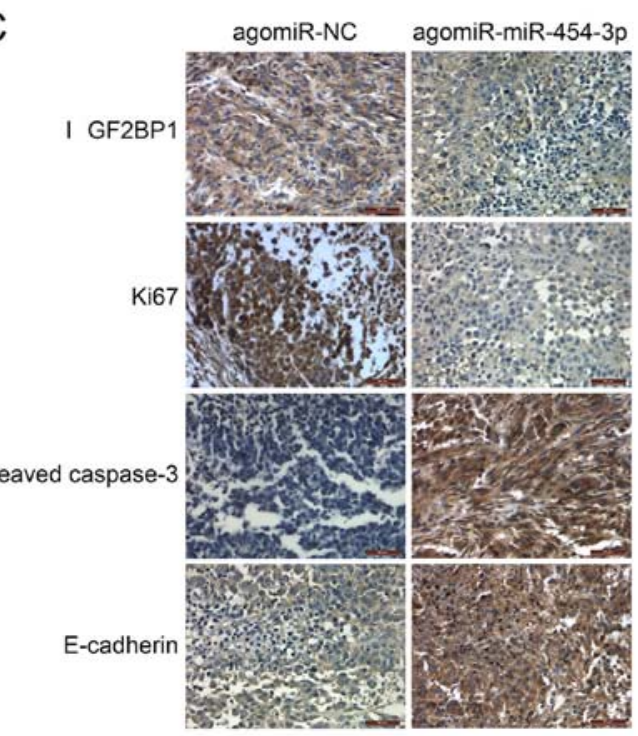

B

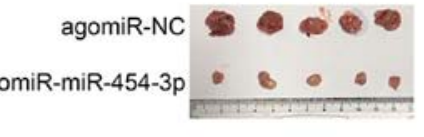

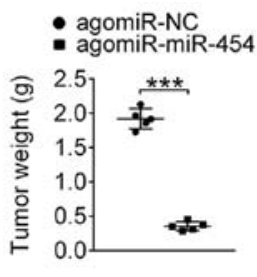
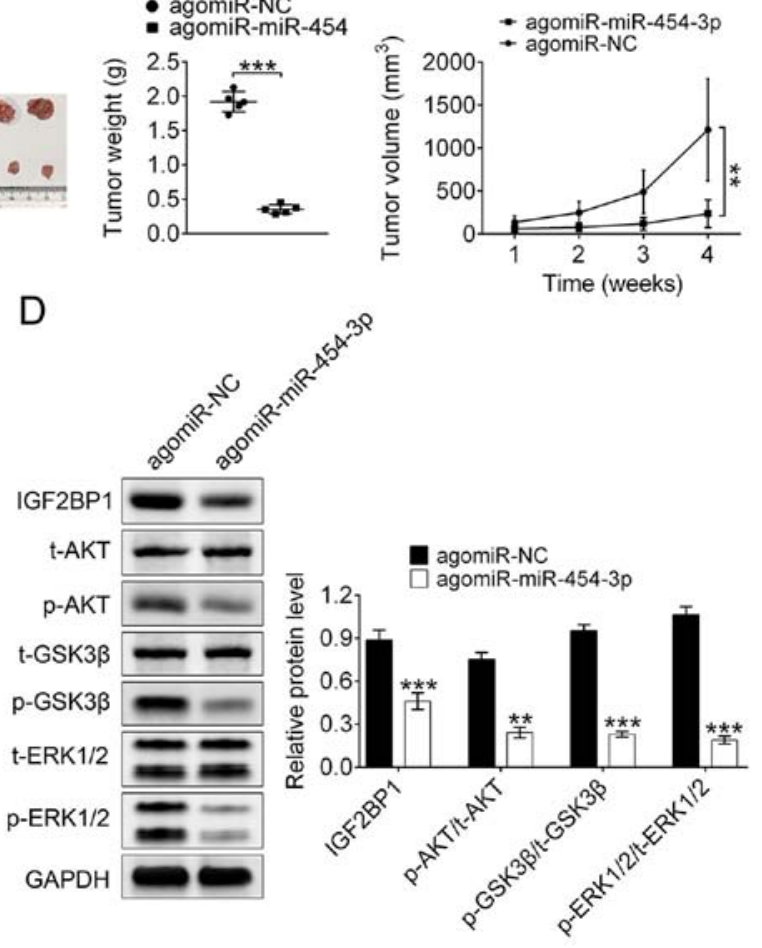

Figure 6. miR-454-3p inhibits tumor growth and metastasis in a subcutaneous xenograft esophageal cancer model in vivo. (A) Reverse transcription-quantitative PCR was used to analyze the relative expression levels of miR-454-3p in the xenograft tumor model in nude mice. (B) Effects of miR-454-3p on the tumor weight and volume of the subcutaneous xenograft tumor model in nude mice induced by TE-1 cells. (C) Immunohistochemical analysis detected the effects of miR-454-3p on the tumor growth. (D) Western blotting was used to analyze the average expression difference of related protein levels of the ERK and AKT signaling pathways in xenograft tumor mice. Results are presented as mean $\pm \mathrm{SD}$. ${ }^{* *} \mathrm{P}<0.01$ and ${ }^{* * *} \mathrm{P}<0.001$ vs. control. miR, microRNA; $\mathrm{NC}$, negative control; t-, total; p-, phosphorylated.

while another study demonstrated miR-454-3p suppressed the progression of lung cancer by targeting Calbindin 1 (27). Besides, other target genes, such as BTG1, Stat3 and Atg12, were also found to be regulated by miR-454-3p in chondrosarcoma initiation and progression (25). The aforementioned studies have documented that miR-454-3p regulated tumor cell growth and invasion by targeting different downstream genes via different signaling pathways. However, the precise molecular mechanisms of miR-454-3P as well as its direct target in ESCA still remain unclear.

In the present study, RT-qPCR and western blot assays revealed that the gene and protein expression levels of miR-454-3p were lower in tumor tissues from ESCA patients and ESCA cells compared with healthy tissues and cells. Moreover, survival rate analysis indicated that low miR-454-3p expression improved the survival time of patients with ESCA compared with those with high expression. Therefore, it was hypothesized that miR-454-3p was an important biomarker for diagnosis of ESCA patients and its overexpression could induce the tumor growth inhibition. The evaluations of cell proliferation, migration and invasion were detected using CCK-8, colony formation, wound healing and Transwell assays, respectively, with four ESCA cells (EC9706, ECA109, TE-1 and TE-8). The in vitro results demonstrated that miR-454-3p-overexpression inhibited ESCA cell proliferation, and decreased the number of migrating and invasive cells; however, these effects could be reversed by deregulating the miR-454-3p expression. Besides, the apoptosis assay for EC9706, ECA109, TE-1 and TE- 8 cells indicated that miR-454-3P was an apoptosis promotor in tumor cell metabolism. The in vitro results were consistent with a previous study (25) regarding the suppressive function of miR-454-3p in tumor proliferation, migration and invasion.

$I G F 2 B P 1$, a post-transcriptional regulator, has been identified in numerous types of cancer, such as lung (28), liver (29) and breast cancer (30), and functions as a carcinogenic gene to accelerate cell proliferation and invasion (31). IGF2BP1 is regulated by a variety of miRNAs, thus affecting the occurrence and development of tumors. For example, the upregulation of miR-150 (32) or miR-491-5p (28) suppressed osteosarcoma and lung cancer cells proliferation, respectively, by directly targeting IGF2BP1. The present bioinformatics prediction revealed miR-454-3p could directly bind to the 3'UTR of wild-type IGF2BPI and miR-454-3p-overexpression significantly inhibited the expression of $I G F 2 B P I$ in ESCA cells in vitro, which is similar with the aforementioned previous studies. In addition, RT-qPCR and western blot assays demonstrated that the overexpression or inhibition of miR-454-3p resulted in the downregulation or upregulation of IGF2BP1, respectively. Meanwhile, Spearman's correlation analysis also demonstrated a significant negative correlation between IGF2BP1 and miR-454-3p expression in tumor tissues from 40 patients with ESCA. It was therefore 
hypothesized that IGF2BP1 was a direct downstream target for miR-454-3p.

To further confirm the function of miR-454-3p in ESCA, the proliferation rate of TE-1 ESCA cancer cells with or without antagomiR-454-3p was calculated after subcutaneous implantation into male BALB/c-nude mice. The RT-qPCR assay for all experimental mice showed that miR-454-3p-overexpression inhibited tumor cell proliferation and migration, and this was consistent with the results in vitro. Immunohistochemical staining illustrated that tumor tissues derived from mice treated with antag-miR-454-3p ESCA cancer cells showed higher expression levels of activated caspase-3 and E-cadherin as well as lower expression levels of Ki-67 compared with those in the control group. Notably, other studies have reported that miRNAs directly targeted IGF2BP1 via suppressing the phosphorylation of AKT pathway or both AKT and ERK pathways to accelerate tumor cells proliferation and migration $(33,34)$. The present western blot analysis reported that the overexpression of miR-454-3p decreased IGF2BP1 expression and activated the protein expression of downstream target genes $\mathrm{p}-\mathrm{AKT}$, p-GSK3 and p-ERK1/2, both in the ERK and AKT signaling pathways. Taken together, these data demonstrated that miR-454-3p suppressed ESCA cell proliferation, migration and apoptosis by targeting IGF2BP1 via the ERK and AKT signaling pathways in vivo.

In summary, it was reported that miR-454-3p had lower expression in ESCA tissues and cells. The results further confirmed that miR-454-3p was associated with clinical features and prognosis of patients with ESCA. Notably, miR-129-5p could suppress the proliferation, migration, and invasion and accelerate apoptosis in ESCA cells in vitro. More importantly, further in vitro and in vivo studies revealed that miR-454-3p suppressed ESCA cell proliferation, migration and apoptosis by targeting IGF2BP1 via the ERK and AKT pathways. Taking these finds together, the present study demonstrated miR-454 may be a useful biomarker and may improve our understanding of the molecular pathogenesis of ESCA. This may enable further development of novel therapies for patients with ESCA.

\section{Acknowledgements}

Not applicable.

\section{Funding}

The present study was funded by the Municipal Science and Technology Plan (Guidance) Project of Nantong City in 2014 (grant no. HS149147)

\section{Availability of data and materials}

All data generated or analyzed during this study are included in this published article.

\section{Authors' contributions}

YZ conceived and designed the experiments. AY performed the statistical analysis. CW and LZ analyzed and interpreted the results of the experiments. $\mathrm{JZ}$ and $\mathrm{YZ}$ performed the experiments. YZ and AY wrote the manuscript. All authors read and approved the final manuscript.

\section{Ethics approval and consent to participate}

The present study was approved by The Ethics Committee of Affiliated Haian Hospital of Nantong University (Nantong, China). All animal experiment protocols were approved by the Ethics Committee of Affiliated Haian Hospital of Nantong University.

\section{Patient consent for publication}

Not applicable.

\section{Competing interests}

The authors declare that they have no competing interests.

\section{References}

1. Thrift AP and Whiteman DC: The incidence of esophageal adenocarcinoma continues to rise: Analysis of period and birth cohort effects on recent trends. Ann Oncol 23: 3155-3162, 2012.

2. Ferlay J, Soerjomataram I, Dikshit R, Eser S, Mathers C, Rebelo M, Parkin DM, Forman D and Bray F: Cancer incidence and mortality worldwide: Sources, methods and major patterns in GLOBOCAN 2012. Int J Cancer 136: E359-E386, 2015.

3. Kim T, Grobmyer SR, Smith R, Ben-David K, Ang D, Vogel SB and Hochwald SN: Esophageal cancer-the five year survivors. J Surg Oncol 103: 179-183, 2011.

4. Iorio MV and Croce CM: MicroRNA dysregulation in cancer: Diagnostics, monitoring and therapeutics. A comprehensive review. EMBO Mol Med 4: 143-159, 2012.

5. Ambros V: The functions of animal microRNAs. Nature 431: 350-355, 2004.

6. Bartel DP: MicroRNAs: Genomics, biogenesis, mechanism, and function. Cell 116: 281-297, 2004.

7. Wang S, Zhang G, Zheng W, Xue Q, Wei D, Zheng Y and Yuan J: MiR-454-3p and miR-374b-5p suppress migration and invasion of bladder cancer cells through targetting ZEB2. Biosci Rep 38: BSR20181436, 2018.

8. Wu X, Ding N, Hu W, He J, Xu S, Pei H, Hua J, Zhou G and Wang J: Down-regulation of BTG1 by miR-454-3p enhances cellular radiosensitivity in renal carcinoma cells. Radiat Oncol 9: 179, 2014

9. Yisraeli JK: VICKZ proteins: A multi-talented family of regulatory RNA-binding proteins. Biol Cell 97: 87-96. 2005.

10. Bell JL, Wachter K, Muhleck B, Pazaitis N, Kohn M, Lederer M and Huttelmaier S: Insulin-like growth factor 2 mRNA-binding proteins (IGF2BPs): Post-transcriptional drivers of cancer progression? Cell Mol Life Sci 70: 2657-2675, 2013.

11. Vainer G, Vainer-Mosse E, Pikarsky A, Shenoy SM, Oberman F, Yeffet A, Singer RH, Pikarsky E and Yisraeli JK: A role for VICKZ proteins in the progression of colorectal carcinomas: Regulating lamellipodia formation. J Pathol 215: 445-456, 2008.

12. Huttelmaier S, Zenklusen D, Lederer M, Dictenberg J, Lorenz M, Meng X, Bassell GJ, Condeelis J and Singer RH: Spatial regulation of beta-actin translation by Src-dependent phosphorylation of ZBP1. Nature 438: 512-515, 2005.

13. Stohr N, Kohn M, Lederer M, Glass M, Reinke C, Singer RH and Huttelmaier S: IGF2BP1 promotes cell migration by regulating MK5 and PTEN signaling. Genes Dev 26: 176-189, 2012.

14. Su Y, Xiong J,Hu J, Wei X, Zhang X and Rao L: MicroRNA-140-5p targets insulin like growth factor 2 mRNA binding protein 1 (IGF2BP1) to suppress cervical cancer growth and metastasis. Oncotarget 7: 68397-68411, 2016.

15. Bando E, Makuuchi R, Irino T, Tanizawa Y, Kawamura T and Terashima M: Validation of the prognostic impact of the new tumor-node-metastasis clinical staging in patients with gastric cancer. Gastric Cancer 22: 123-129, 2019. 
16. Chen J, Ren X, Li L, Lu S, Chen T, Tan L, Liu M, Luo Q, Liang S, Nie $Q$, et al: Integrative analyses of mRNA expression profile reveal the involvement of IGF2BP1 in chicken adipogenesis. Int J Mol Sci 20: 2923, 2019.

17. Livak KJ and Schmittgen TD: Analysis of relative gene expression data using real-time quantitative PCR and the 2(-Delta Delta $\mathrm{C}(\mathrm{T})$ ) method. Methods 25: 402-408, 2001.

18. Lang B and Zhao S: miR-486 functions as a tumor suppressor in esophageal cancer by targeting CDK4/BCAS2. Oncol Rep 39: 71-80, 2018.

19. Jung HK, Tae CH, Lee HA, Lee H, Don Choi K, Park JC, Kwon JG, Choi YJ, Hong SJ, Sung J, et al: Treatment pattern and overall survival in esophageal cancer during a 13-year period: A nationwide cohort study of 6,354 Korean patients. PLoS One 15: e0231456, 2020

20. Lin Y, Totsuka Y, Shan B, Wang C, Wei W, Qiao Y, Kikuchi S, Inoue $\mathrm{M}$, Tanaka $\mathrm{H}$ and $\mathrm{He} \mathrm{Y}$ : Esophageal cancer in high-risk areas of China: Research progress and challenges. Ann Epidemiol 27: 215-221, 2017.

21. Gomez-Gomez Y, Organista-Nava J and Gariglio P: Deregulation of the miRNAs expression in cervical cancer: Human papillomavirus implications. Biomed Res Int 2013: 407052, 2013.

22. Riquelme I, Letelier P, Riffo-Campos AL, Brebi P and Roa JC: Emerging role of miRNAs in the drug resistance of gastric cancer. Int J Mol Sci 17: 424, 2016.

23. Hu Y, Correa AM, Hoque A, Guan B, Ye F, Huang J, Swisher SG, Wu TT, Ajani JA and Xu XC: Prognostic significance of differentially expressed miRNAs in esophageal cancer. Int J Cancer 128: 132-143, 2011.

24. Murakami Y, Yasuda T, Saigo K, Urashima T, Toyoda H, Okanoue $\mathrm{T}$ and Shimotohno K: Comprehensive analysis of microRNA expression patterns in hepatocellular carcinoma and non-tumorous tissues. Oncogene 25: 2537-2545, 2006.

25. Bao X, Ren T, Huang Y, Sun K, Wang S, Liu K, Zheng B and Guo W: Knockdown of long non-coding RNA HOTAIR increases miR-454-3p by targeting Stat 3 and Atg12 to inhibit chondrosarcoma growth. Cell Death Dis 8: e2605, 2017.

26. Shao Y, Liang B, Long F and Jiang SJ: Diagnostic MicroRNA biomarker discovery for non-small-cell lung cancer adenocarcinoma by integrative bioinformatics analysis. Biomed Res Int 2017: 2563085, 2017.
27. Jin $\mathrm{C}$, Lin $\mathrm{T}$ and Shan L: Downregulation of calbindin 1 by miR-454-3p suppresses cell proliferation in nonsmall cell lung cancer in vitro. Cancer Biother Radiopharm 34: 119-127, 2019.

28. Gong F, Ren P,Zhang Y,Jiang J and Zhang H: MicroR NAs-491-5p suppresses cell proliferation and invasion by inhibiting IGF2BP1 in non-small cell lung cancer. Am J Transl Res 8: 485-495, 2016.

29. Zhou X, Zhang CZ, Lu SX, Chen GG, Li LZ, Liu LL, Yi C, Fu J, Hu W, Wen JM and Yun JP: miR-625 suppresses tumour migration and invasion by targeting IGF2BP1 in hepatocellular carcinoma. Oncogene 35: 5078, 2016.

30. Fakhraldeen SA, Clark RJ, Roopra A, Chin EN, Huang W, Castorino J, Wisinski KB, Kim T, Spiegelman VS and Alexander CM: Two isoforms of the RNA binding protein, coding region determinant-binding protein (CRD-BP/IGF2BP1), are expressed in breast epithelium and support clonogenic growth of breast tumor cells. J Biol Chem 290: 13386-13400, 2015.

31. Stohr N and Huttelmaier S: IGF2BP1: A post-transcriptional 'driver' of tumor cell migration. Cell Adh Migr 6: 312-318, 2012.

32. Qu Y, Pan S, Kang M, Dong R and Zhao J: MicroRNA-150 functions as a tumor suppressor in osteosarcoma by targeting IGF2BP1. Tumour Biol 37: 5275-5284, 2016.

33. Zhang J, Cheng J, Zeng Z, Wang Y, Li X, Xie Q, Jia J, Yan Y, Guo Z, Gao J, et al: Comprehensive profiling of novel microRNA-9 targets and a tumor suppressor role of microRNA-9 via targeting IGF2BP1 in hepatocellular carcinoma. Oncotarget 6: 42040-42052, 2015

34. Qin X, Sun L and Wang J: Restoration of microRNA-708 sensitizes ovarian cancer cells to cisplatin via IGF2BP1/Akt pathway. Cell Biol Int 41: 1110-1118, 2017.

This work is licensed under a Creative Commons Attribution-NonCommercial-NoDerivatives 4.0 International (CC BY-NC-ND 4.0) License. 